\title{
The Extend of Awareness Among Dental Students on The Muscculoskeletal Occupational Hazards Associated With Their Profession- A Questonnnaire Survey
}

Saravana Kumar ${ }^{1}$, Sosa George ${ }^{2}$

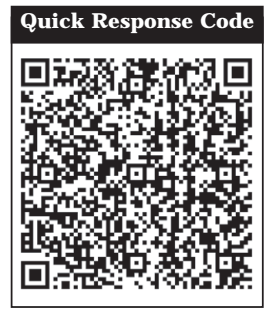

doi: $10.5866 / 2015.7 .10116$

'Senior Lecturer

2Undergraduate student,

Department of Anatomy

Saveetha Dental College,

Velappanchavadi

Chennai-6000

\section{ABSTRACT:}

BACKGROUND: Musculoskeletal disorders are one of the common kinds of occupational hazards associated with dentistry. The signs and symptoms start right from the time students enter clinics. It is important to assess the extent of awareness among dental students on this issue and to understand the prevalence of early signs and symptoms of musculoskeletal disorders among students.

AIMS: The present study was aimed at understanding the extend of awareness among dental students on musculoskeletal occupational hazards and also to analyse the prevalence of early signs of musculoskeletal disorders among them.

MATERIALS AND METHOD: The study was conducted on 200 students of Saveetha Dental College, Chennai, I ndia. The students were categorised into four groups, each containing 50 participants. The grouping was done based on year of study. Each student was asked to fill up a self-administrated questionnaire. The data was compiled and statistical analysis was performed with MS officeExcel.

RESULTS: All the participants in all groups reported that they are awarethat thereis risk of developing musculoskel etal disorders associated with their profession. Only $45.5 \%$ of the subjects said that they had received education on musculoskel etal occupational hazards before they started with clinical practice. $87.5 \%$ of the students had symptoms in back and shoulder region. $87 \%$ of the students experienced pain in neck. $86.5 \%$ people experienced pain or paraesthesia of fingers and $85.5 \%$ people had pain or paraesthesia in hands. $92 \%$ of the subjects were aware that there arevarious types of exercises through which the onset and progress of musculoskeletal disorders can be prevented.

CONCLUSION: Early signs and symptoms of musculoskeletal disorders are highly prevalent among dental students. It is important to ensure that the awareness reaches the students right from the time they start working in clinic.

Key words: Musculoskel etal disorder, occupational hazard, Ergonomics, Posture 


\section{Introduction:}

Dentistry is a profession where the practitioners are at a considerable risk of being subjected to various occupational hazards. Musculoskeletal disorders arethe most common form of occupational hazards in dentistry. It's al so one of the first to show manifestations. I mproper postures, long periods of repetitive hand and finger movements are chief causes for musculoskeletal disorders. Myofascial pain disorder, cervical spondylitis, thoracic outlet syndrome, rotatory cuff tendonitis, DeQuervain's disease and carpel tunnel syndrome are some of the musculoskel etal disorders associated with the profession. ${ }^{1}$ There are numerous muscle relaxants and strengthening exercises which when performed on a regular basis can prevent the onset and arrest the progression of musculoskeletal disorders.

The postural habits and techniques a dentist learns during the early days of clinical practice while he is a student is likely to get continued for the rest of his career. Hence it is important to ensure that thestudents are learning the correct techniques and postures and are implementing them during their practice. The present study was aimed at understanding the extend of awareness among dental students on musculoskeletal occupational hazards and also to analyse the prevalence of early signs of musculoskeletal disorders among them.

\section{Materials and methods:}

A total of 200 dental students from Saveetha Dental College, Chennai took part in thestudy. Only those students from third year BDS to MDS were included in the study. This is because only these group of students work in clinics. The subjects were categorized into 4 groups. Group A had third year BDS students, fourth year BDS students were put in group B and interns in group C. All the MDS students were put in group D irrespective of their area of specialization. Each group had 50 participants.

Each subject was requested to fill up a selfadministrated questionnaire which contained 18 questions. The questions wereabout their knowledge on musculoskel etal occupational hazards, its preventive exercises, the frequency in which they perform it, the basic ergonomics, chair positions, grasps, indirect visualization, use of dental loops etc. The subjects were also questioned on the signs and symptoms of musculoskel etal disorders they may be experiencing.

The data was compiled and statistical analysis was performed using MS office Excel. Tables and illustrations were made wherever required.

\section{Results:}

Out of 200 students who participated in the study, $31.5 \%$ were male and $68.5 \%$ were female. Each group had 50 candidates each. All the participants in all groups reported that they are aware that there is risk of developing musculoskeletal disorders associated with their profession. Only $45.5 \%$ of the subjects said that they had received education on musculoskeletal occupational hazards before they started with clinical practice. The number of students who received this education seemed to be decreasing from group D to group A. Graph 1 shows the percentage of students who received education on occupational hazards in each category.

Out of all the candidates $24.5 \%$ were not familiar with the concept of ergonomics. All the MDS students think that it is of utmost importance in clinical practice whereas only $60 \%$ of the $3^{\text {rd }}$ year BDS students are aware about the importance of it. There is an increase in awareness about ergonomics from group A to group D. Graph 2 shows the percentage of awareness about ergonomics among dental students.

When questioned on chair positions, $40 \%$ of the participants said that they were somewhat aware of the various chair position guidelines, whereas $59 \%$ said they were very much aware of the same. $1 \%$ of the participants said that they were not much aware of chair positions and that they work in whatever positions they feel comfortable (Graph 3).

The percentage of students who follow chair position guidelines and grasping techniques seemed to be increasing from group $A$ to group $B$. Whereas the number of people who use dental loops seemed to be decreasing from group $A$ to group $D$. It was also found out that the percentage of people who are comfortable while working under indirect vision 
also increases from group $A$ to group $D$. There found to be much difference in the incidence of the symptoms of musculoskeletal deformity (Graph 4).

$94.5 \%$ of all the students have experienced symptoms of muscul oskel etal disorders. It was found that back and shoulders are the sites where maximum number of people had pain, paraesthesia or numbness. $87.5 \%$ of the people had symptoms in back and shoulder region. $87 \%$ of the patients experienced pain in neck. 86.5\% people experienced pain or paraesthesia of fingers and $85.5 \%$ people had pain or paraesthesia in hands. Only $42 \%$ of people had pain or paraesthesia of legs after long hours of treating patients in clinics (Graph 5).

Only $6 \%$ of all the subjects have consulted a doctor due to musculoskel etal pain paraesthesia or numbness. Of this $6 \%$, maximum number was constituted by MDS students (Table 1 ).

$92 \%$ of the subjects were aware that there are various types of exercises through which the onset and progress of musculoskeletal disorders can be prevented. But only $17.4 \%$ of them did the exercises regularly. Many of those who did not perform the exercises regularly reported that they have inadequate information on how to perform these exercises (Table 2).

\section{Discussion:}

The study analysed the extend of awareness among dental students on the various musculoskel etal occupational hazards associated with their profession, the measures they take to prevent it and the incidence of early signs and symptoms of musculoskeletal disorders through a self-administrated questionnaire. All the participants were chosen randomly. Some of the students were found to be less informed on the seriousness of musculoskeletal occupational hazards. Everyone is aware that there is possible risk of devel oping muscul oskeletal disorder. But the depth of this awareness is minimal in third year students. It is found to be increasing to moderate to adequate levels as the seniority increases. This variation may be the result of increased experience. The comfort in practicing the various chair positions, grasps, indirect vision seemed to be increasing from

Tablel: The number of students who follow chair position guidelines, grasping techniques, use dental loops and indirect visualisation.

\begin{tabular}{l|cccc|cccc|ccc|c|cccc} 
& \multicolumn{4}{|c}{ Always } & \multicolumn{4}{c|}{ Most of the time } & \multicolumn{4}{c}{ Sometimes } & \multicolumn{4}{c}{ Rarely } \\
& A & B & C & D & A & B & C & D & A & B & C & D & A & B & C & D \\
\hline Chair position & 8 & 17 & 23 & 43 & 30 & 28 & 23 & 7 & 12 & 5 & 5 & 0 & 0 & 0 & 0 & 0 \\
\hline Grasps & 4 & 14 & 21 & 28 & 30 & 22 & 25 & 21 & 16 & 14 & 4 & 1 & 0 & 0 & 0 & 0 \\
\hline Loops & 16 & 15 & 14 & 11 & 26 & 26 & 21 & 18 & 6 & 7 & 8 & 10 & 2 & 5 & 7 & 11 \\
\hline Indirect vision & 8 & 11 & 21 & 38 & 26 & 28 & 26 & 8 & 16 & 11 & 3 & 4 & 0 & 0 & 0 & 0 \\
\hline
\end{tabular}

Table 2: Table showing the number of participants in each group to experience pain, numbness or paraesthesia in different parts of the body along with the frequency of its incidence

\begin{tabular}{l|cccc|cccc|cccc|ccc|c} 
& \multicolumn{4}{|c}{ Never } & \multicolumn{4}{c}{ sometimes } & \multicolumn{4}{c}{ Often } & \multicolumn{4}{c}{ Always } \\
& A & B & C & D & A & B & C & D & A & B & C & D & A & B & C & D \\
\hline Back & 7 & 5 & 8 & 5 & 22 & 23 & 23 & 22 & 17 & 16 & 14 & 16 & 4 & 6 & 5 & 7 \\
\hline Fingers & 7 & 6 & 7 & 7 & 27 & 28 & 26 & 29 & 12 & 14 & 13 & 10 & 4 & 2 & 4 & 4 \\
\hline Hands & 8 & 6 & 7 & 8 & 28 & 29 & 27 & 30 & 12 & 12 & 12 & 9 & 2 & 3 & 4 & 3 \\
\hline shoulders & 6 & 4 & 5 & 10 & 22 & 30 & 30 & 35 & 14 & 12 & 20 & 0 & 8 & 4 & 5 & 5 \\
\hline Neck & 7 & 8 & 5 & 6 & 24 & 26 & 25 & 21 & 17 & 14 & 15 & 17 & 2 & 4 & 5 & 6 \\
\hline Legs & 29 & 27 & 30 & 30 & 19 & 21 & 18 & 17 & 2 & 2 & 2 & 3 & 0 & 0 & 0 & 0 \\
\hline
\end{tabular}




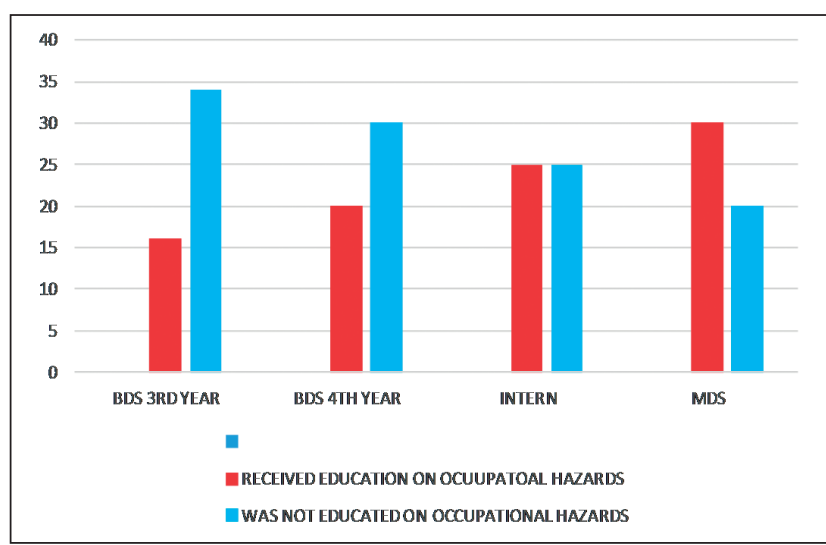

Graph 1: The percentage of students who received education on occupational hazards in each group

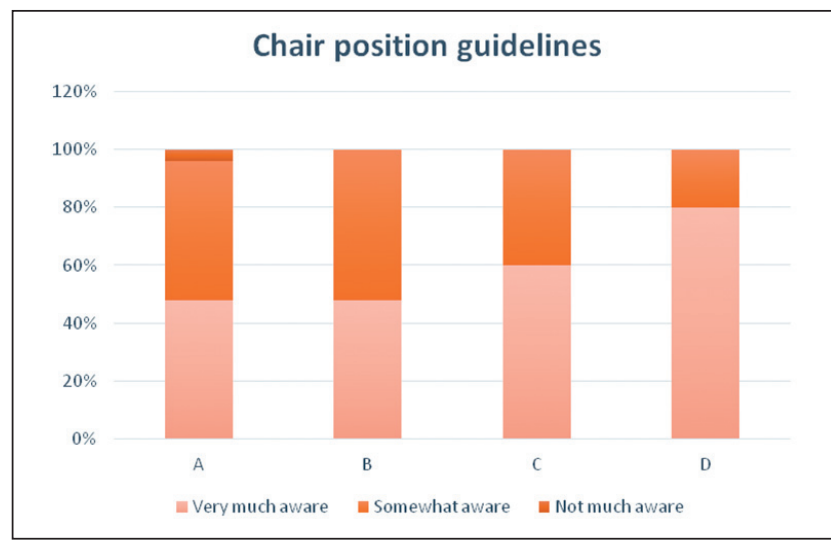

Graph 3: Extend of awareness on chairposition guidelines on various groups of students.

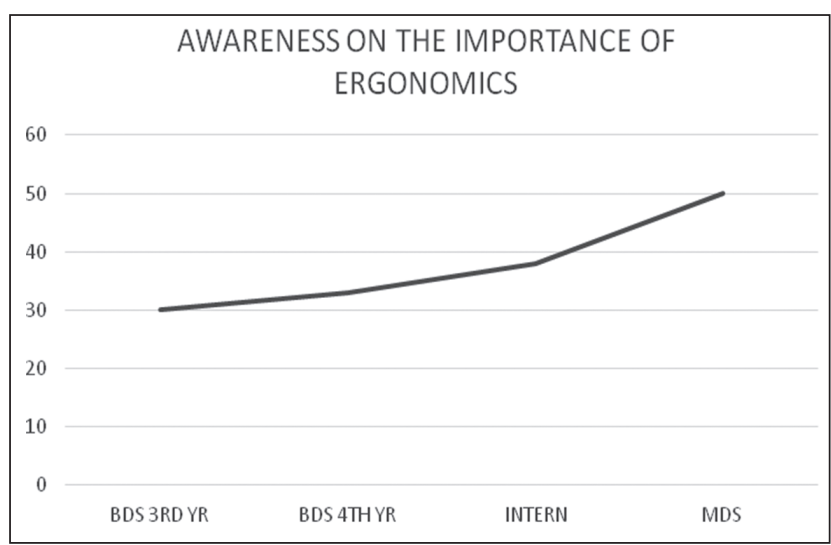

Graph 2: Extend of awareness about ergonomics among different groups

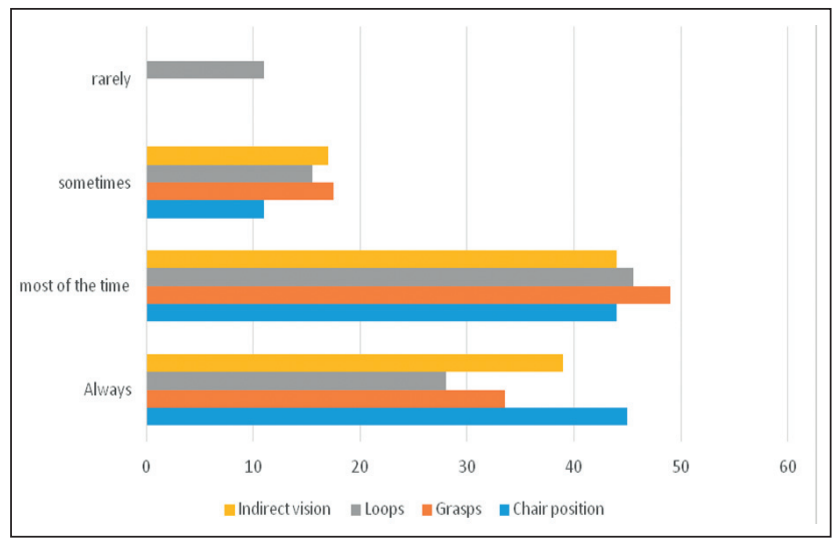

Graph 4: The total number of students and the frequency at which they use indirect vision, loops, grasps and chair postition

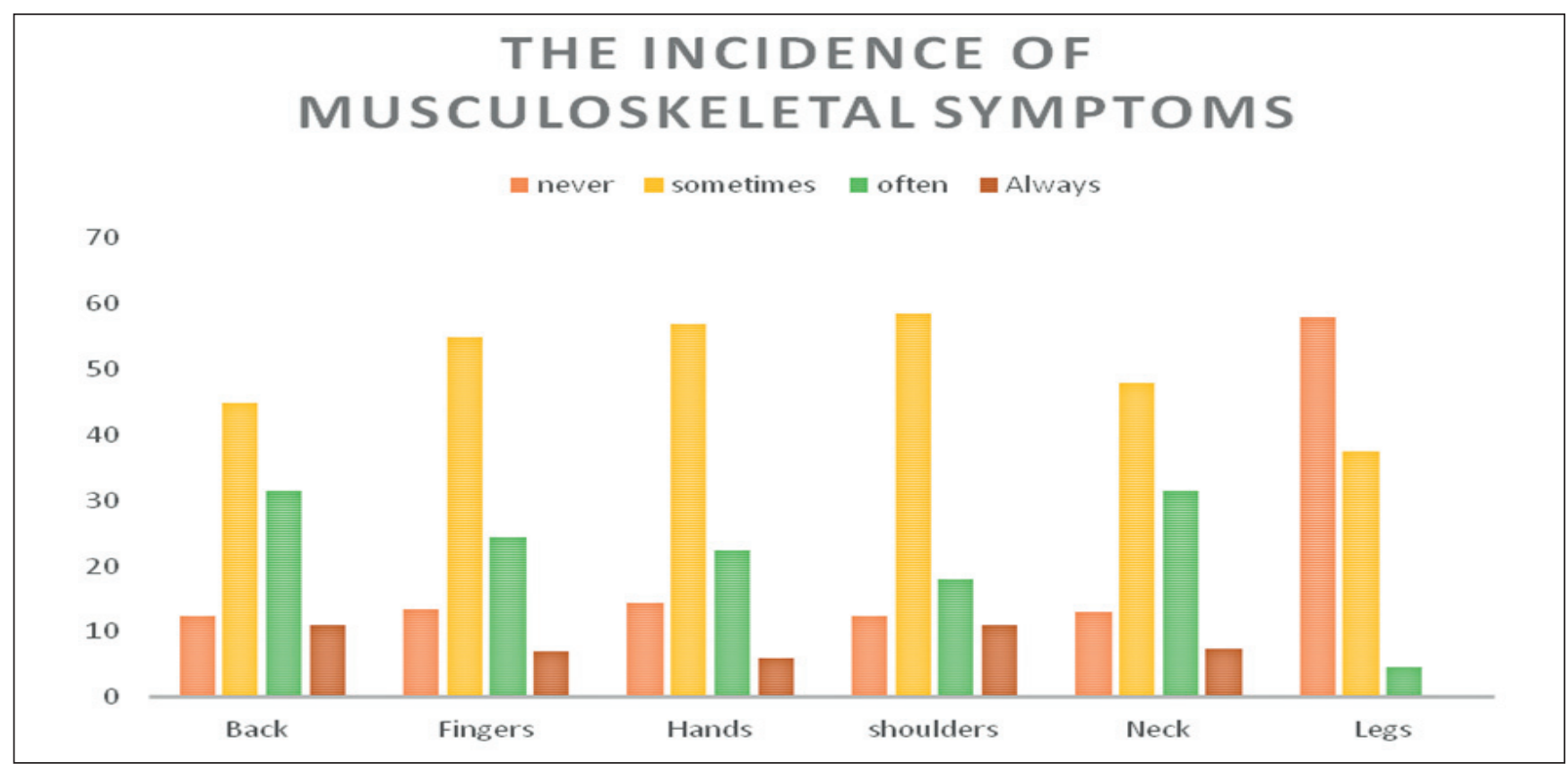

Graph 5: Chart showing the incidence of musculoskeltal symptoms among various groups. 
third year undergraduates to post graduates. Many students who correctly practiced the ergonomic guidelines seemed to be devoid of any sign and symptom of musculoskeletal disorder. Whereas all of the students who did not follow these guidelines had at least one form of musculoskeletal symptom. Most of the participants reported that they have experienced at least some sort of pain, numbness or paraesthesia of their body parts after long hours of clinical work.

Many studies conducted on work related musculoskeletal disorders among dental students and dentists in different parts of the world showed similar results. In a study conducted among the dental students from 5 dental schools in Malaysia, $93 \%$ of the dinical year students showed symptoms of work related musculoskeletal disorders. There was found to be a female predilection for the symptoms. Neck and lower back regions were the regions were symptoms were most common. ${ }^{2}$ Another study on the musculoskeletal disorders among dental practitioners in Andhra Pradesh, India showed the increased incidence of symptoms in neck, lower back followed by shoulders and wrist. ${ }^{3}$ A study among the postgraduate dental students in China also showed high incidence of muscul oskel etal symptoms in neck shoulders, back, wrist and ankle. ${ }^{4}$ A study conducted among the dental students in Turkey showed that the incidence of musculoskeletal disorder symptoms were more common among left handed students. The position adopted by student was found to have major implication on theintensity of pain. ${ }^{5}$

Thus the results from the current study is correlating with the results obtained from studies conducted among other populations also. I ncreased academic stress on students force students to work for long hours without adequate rest and relaxation. This may be a reason why the incidence of musculoskeletal symptoms is of high prevalence among the student community.

\section{Conclusion:}

It is found that the incidence of musculoskel etal disorders is $94.5 \%$ among the clinical students. The awareness on musculoskeletal occupational hazards seemed to be decreasing from MDS to $3^{\text {rd }}$ year BDS students. It is found that the incidence of musculoskeletal disorders correlates with ergonomics. The longevity of a person's career is dependent on the physical and emotional comfort he has in his work place. Musculoskeletal disorders are one of the reasons why many young dentist leave their profession at a very early stage of their career. It's not just enough to train the students on the various procedures; but it is also equally important to inculcate the importance of following healthy practices. Occupational hazards and the way to prevent them should be made part of the dentistry curriculum.

\section{References:}

1. Leggat PA, Kedjarune U, Smith DR. Occupational health problems in modern dentistry: a review. Ind Health 2007; 45:611-621.

2. Saad A Khan, Kwai Yee Chew. Effect of working characteristics and taught ergonomics on the prevalence of musculoskeletal disorders amongst dental students. BMC Musculoskelet Disord. 2013; 14:118.

3. Gopinadh A1, Devi KN, Chiramana S, Manne P, Sampath A, Babu MS. Ergonomics and musculoskeletal disorder: as an occupational hazard in dentistry. J Contemp Dent Pract 2013; 14:299-303.

4. Jianru YI, Xiangxiang HU, Boxi YAN, Wei ZHENG, Yu LI, Zhihe ZHAO. High and specialty-related musculoskeletal disorders afflict dental professionals even since early training years. J Appl Oral Sci 2013; 21:376-382

5. Tezel A, Kavrut F, Tezel A, Kara C, Demir T, Kavrut R. Musculoskel etal disorders in left- and right-handed Turkish dental students. Int J Neurosci 2005; 115:255-266

\section{Gain quick access to our journal online View our journal at www.nacd.in}

